Synthesis of Natural

Products and

Potential Drugs

\section{Synthesis of Diterpenoid Steenkrotin A}
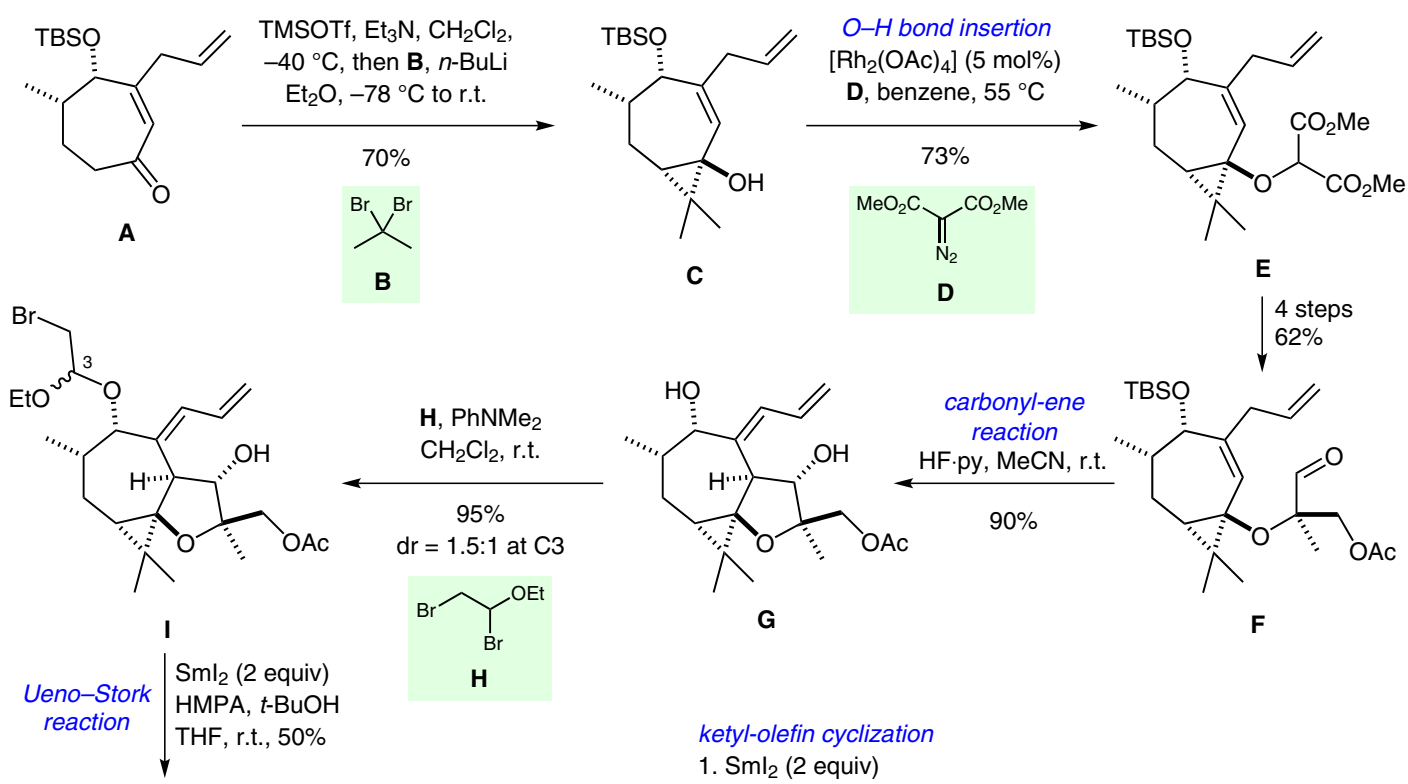

\section{ketyl-olefin cyclization \\ 1. $\mathrm{Sml}_{2}$ (2 equiv) \\ HMPA, $t$-BuOH}

Key words

steenkrotin A

terpenoids

O-H bond insertion

reaction

Ueno-Stork

reaction

ketyl-olefin

cyclization

aldol condensation

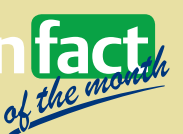

carbonyl-ene

THF, $50^{\circ} \mathrm{C}$

single diastereomer

2. $\mathrm{DMP}, \mathrm{NaHCO}_{3}$ $\mathrm{CH}_{2} \mathrm{Cl}_{2}$
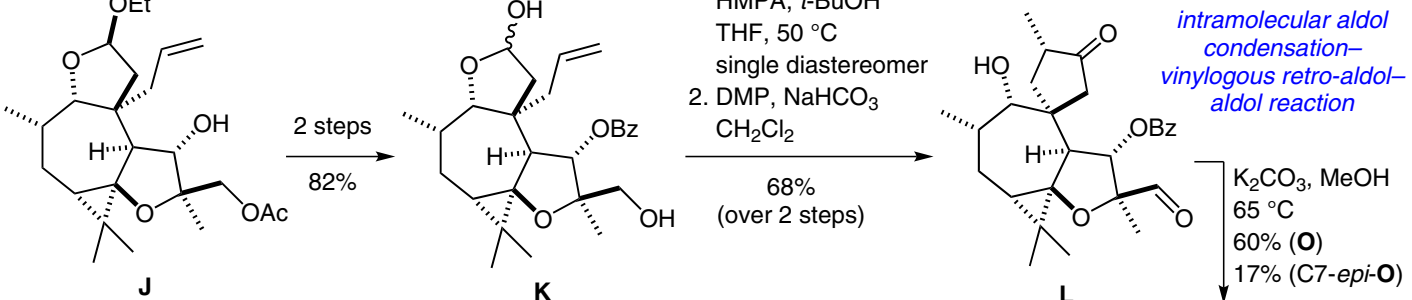

(over 2 steps)

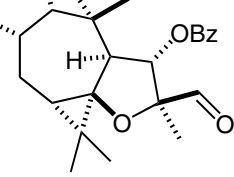

$\mathrm{K}_{2} \mathrm{CO}_{3}, \mathrm{MeOH}$

$65{ }^{\circ} \mathrm{C}$

$60 \%(0)$

17\% (C7-epi-O)

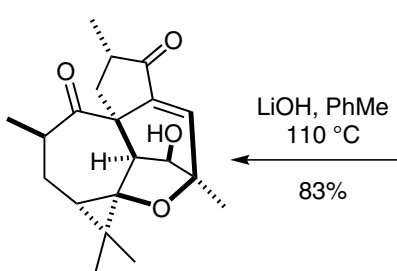

(士)-Steenkrotin A

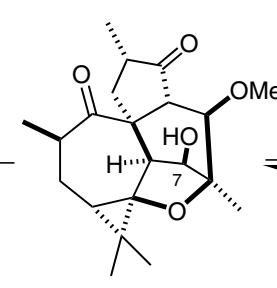

0

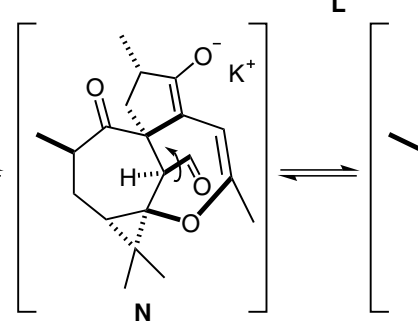

Significance: Ding and co-workers report the first total synthesis of $( \pm)$-steenkrotin $A$, a diterpenoid isolated from an African shrub. Structurally, this natural product is characterized by a pentacyclic skeleton, embedded with a sterically congested tetrahydrofuran moiety. The authors focused first on the construction of tricycle $\mathbf{I}$, which set the stage for further elegant transformations to access the target.

SYNFACTS Contributors: Erick M. Carreira, Stefan Fischer Synfacts 2015, 11(7), 0679 Published online: 17.06.2015 Dol: 10.1055/s-0034-1380895; Reg-No.: C03215SF
Comment: The tetrahydrofuran subunit was installed by a Rh-catalyzed $\mathrm{O}-\mathrm{H}$ bond insertion and a carbonyl-ene reaction. A Sml 2 -mediated UenoStork reaction and a ketyl-olefin cyclization were used to construct spirocycle $\mathbf{L}$. Interestingly, ( $( \pm)$ steenkrotin A could be accomplished by a cascade aldol condensation-vinylogous retro-aldolaldol reaction, followed by elimination. 